\title{
A Study on Innovation in Technology and Design Variation for Super Tall Buildings
}

\author{
Hyeong-Il Kim*1 and Sungwoo Shin ${ }^{2}$ \\ ${ }^{1}$ Research Professor, Sustainable Building Research Center, Hanyang University, Korea \\ ${ }^{2}$ Professor, Department of Architectural Engineering, Hanyang University, Korea
}

\begin{abstract}
The paper presented Design Variation and Technology for Super Tall Buildings, the topic presented in the 12th International Symposium of Korea Super Tall Building Forum by Hyeong-il Kim. In this paper, author review examples of technological innovations in tall building design, illustrating the interaction between architectural form and design tools. It also traces current approaches in architectural form generation and possible design solutions. It is a multidisciplinary problem and an integrated work that involves engineering, architecture, state-of-art construction technology and digital design tools.

The study will show a clear linkage of generative design encouraged by technological innovations to design problems in tall building design practice, in addition to its diversely effected results by computerized design tools and construction using CAD/CAM technology.
\end{abstract}

Keywords: tall buildings; architectural form; generative design; computerized design tool

\section{Introduction}

Tall building design and construction have been influenced by the innovation in new technology and construction materials. However, the diverse architectural styles of tall buildings now seen in current design practice have been influenced by the emerging IT industry and computerized tools.

Recently, the development of tall building forms has been towards the so-called iconic approach to promote design variations and viable technologies. This has led to the research opportunity that emphasizes the integration of new technology from different disciplines to be used in architectural design.

Integrated design processes using such tools are now widely adopted by architects and engineers to provide great opportunities for performance based form exploration in tall building design. This research shall attempt to provide a comprehensive review of generative digital design tools, the design process and its influence on the architectural form of tall buildings. It is also expected to contribute to an understanding of design variations by the current form generation research initiatives on tall building design.

The aim is to move beyond the traditional form generation approaches which are driven by formal

*Contact Author: Hyeong-Il Kim, Research Professor,

Hanyang University

1271 Sa3-dong, Sangnok-gu, Ansan-si, Gyeonggi-do, Korea

Tel: +82-31-400-3741 Fax: +82-31-406-7118

E-mail:kimhyeo@hanyang.ac.kr

(Received April 8, 2010 ; accepted December 1, 2010) and/or functional design considerations to consider generative design as part of the guiding design principles that influence the form exploration process and help realize the architect's conceptual idea.

\section{Generative Architecture}

Generative architecture refers to a practice in which component invention is set in motion with some degree of autonomy and some degree of design control. However, buildings are still governed by good detailing practices such as material limitations, weather resistance, construction tolerances, and feasible construction sequencing (Thurnauer, 2006).

Classical architecture often shows very clear structural influence on the form generation in building design (See Fig.1.). This implies that the form generation process depends heavily upon the limitation
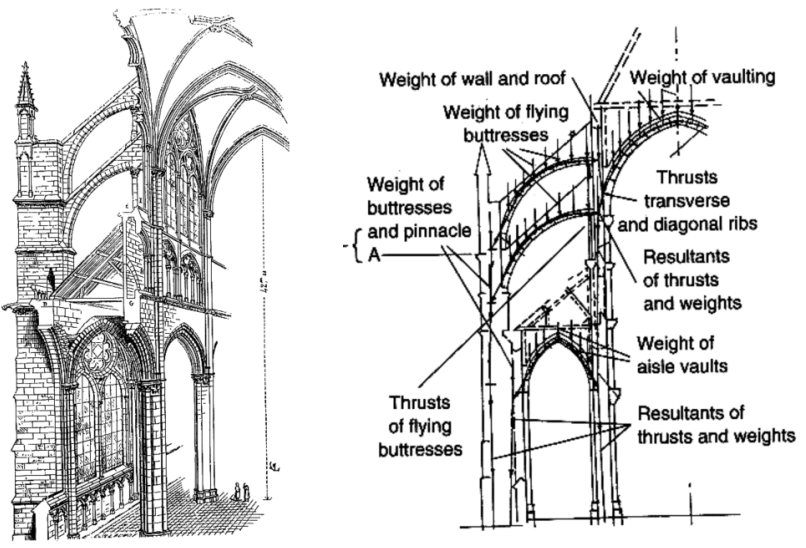

Fig.1. Form Generation by Structural Principal (Source: Schodek, Structures $3^{\text {rd }}$ Edition) 
of the materials and structural character.

Two-dimensional graphic methods have been used from ancient times to find appropriate form and structural consideration at the same time. Although conceptually very simple, graphic approaches to finding the result of force systems are extremely powerful as structural analysis aids. Graphic techniques were used extensively by early investigators in their attempts to understand the behavior of complex structures (Schodek, 1998).

In the modern era, Louis Kahn's and Anne Tying's proposal for a new office building at Philadelphia City Hall is a project referred to as generative architecture (See Fig.2.). The proposed building is described as the product of a constant search for order and structure where the structure is the language used to explore connectivity and growth on a monumental scale (Juarez, 2000).

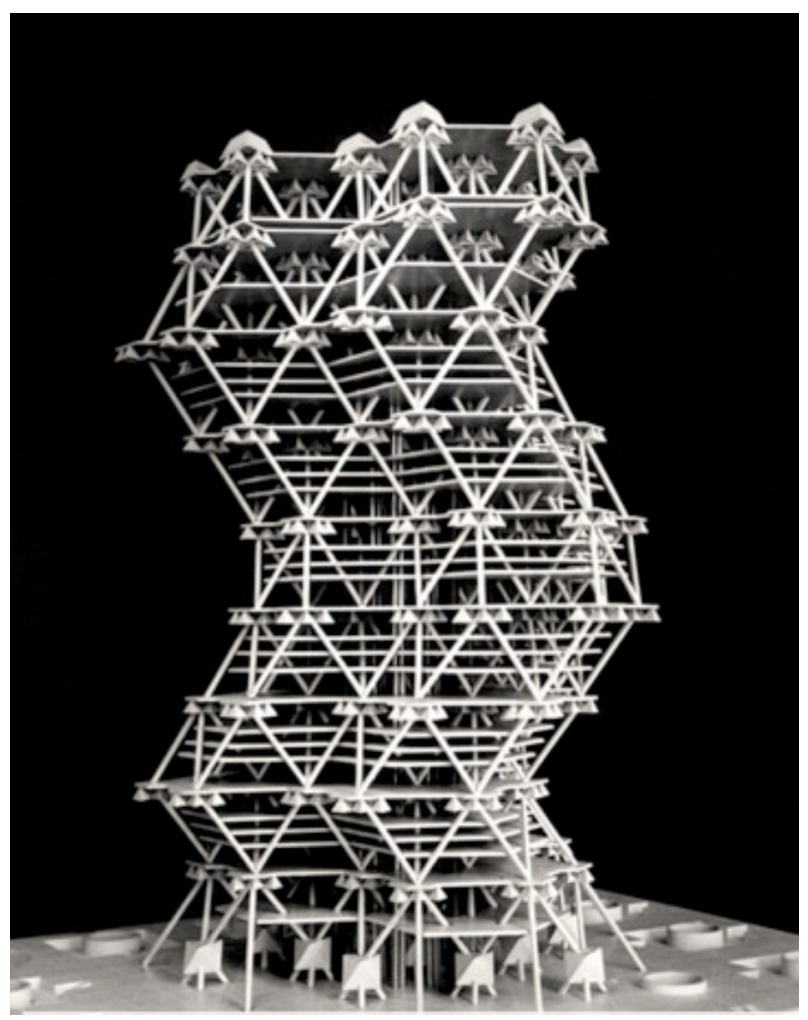

Fig.2. Generative Architecture, Louis Kahn

(Source: http://www.lamastudio.com)

Form generations are often achieved with very simple ideas and logics, which can be seen in folding paper art (See Fig.3.).

However, the design process should not be mystified, because it is a result of the natural evolution of the designer's capabilities to treat the form, from simple to more complex configurations (Kulic, 2000).

The nature of paper folding produces an easy curvature to the model. A rigid three dimensional structure can be generated by tightened or loosed at the edges, pulled at opposite corners to create a twist, and then tightened at both ends.

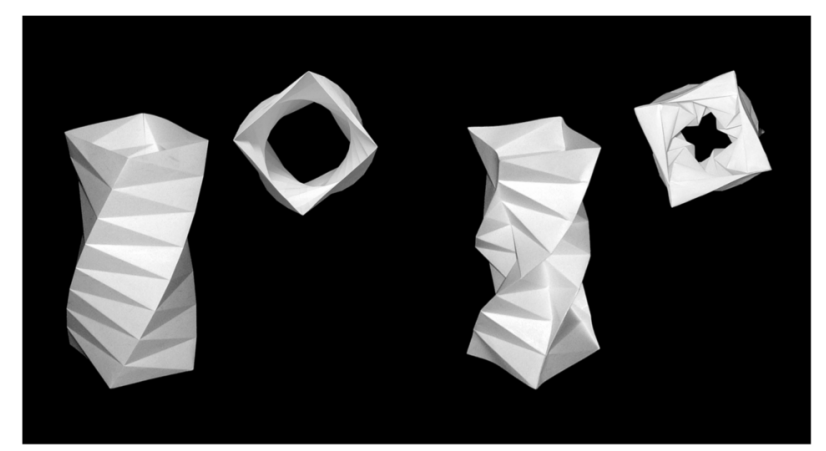

Fig.3. Form Generation by Folding Paper

There have been a number of attempts to capture design motives from nature and to apply them to architectural design. Structures in nature are great lessons for human study. The wholeness of natural forms indicates that the form and forces are always in a state of equilibrium. In most natural forms, the quality of equilibrium may be difficult to recognize. Ms. Maria Andres addressed Architectural DNA, as shown in Fig.4. She observed the organics of nature and translated them into structural elements to generate unique architectural forms (Andres, 2009).
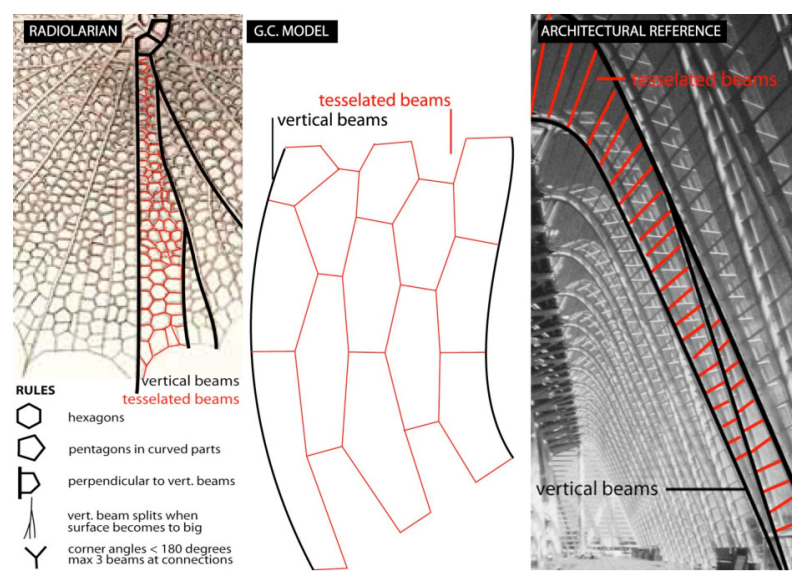

Fig.4. Architectural DNA (Source: Andres M)

Figs.5. and 6. show experimental generative design studio work from the AA School, London and Columbia University, New York. Both studios initiated design by using digital generative design tools to process and define the shape, size and meeting points between the object and the building and the overall intended spatial experience through a 'jig' framework constructed by generative components (Wong, 2008).

\section{Innovations in the Technology of Design Tools}

"Technology transfer" refers to the process whereby the techniques and materials developed in one creative field, industry, or culture are adapted to serve another (Pawley, 1990).

The significance of the influence of computer and IT technology continue to change the practice of architectural design by increasing complexity and enhancing our imagination concerning tall buildings. 


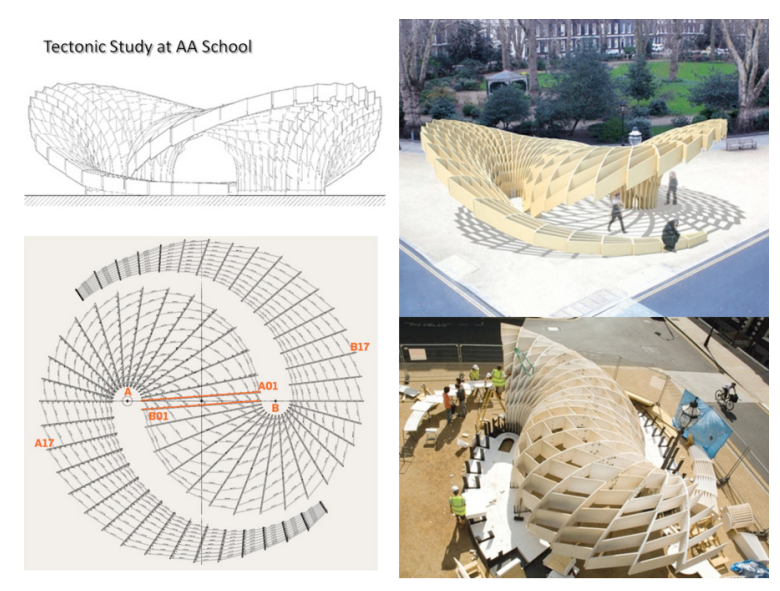

Fig.5. Generative Design Studio (Source: AA School)

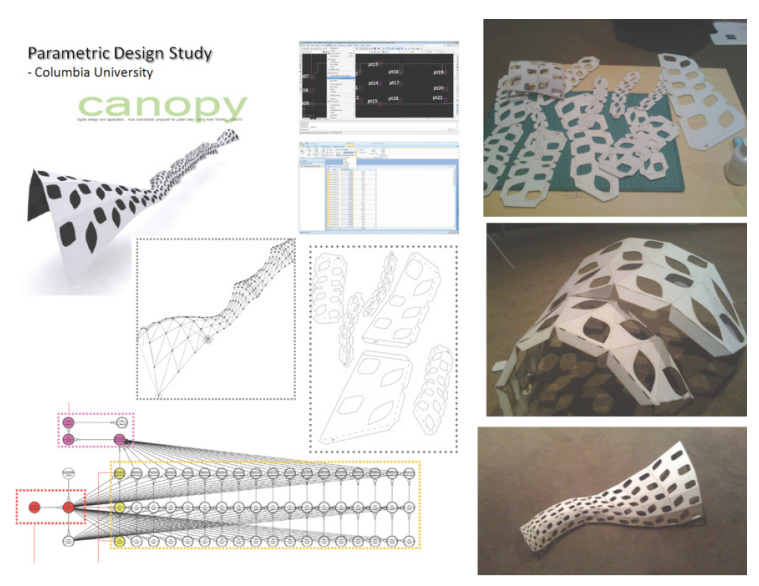

Fig.6. Parametric Design Project

(Source: Parametric Design Study, Columbia University)

Mathematica is a computational software program used in the scientific, engineering, and mathematical fields and other areas of technical computing. It was originally conceived by Stephen Wolfram and developed by Wolfram Research (See Fig.7.).

The software is able to process a number of important mathematical computations including 2D and 3D data and function visualization, continuous and discrete integral transforms that can be usefully applied to architectural geometric studies. The development of constructive methods and skills is without doubt connected with CAD programs. However, it is an ideal program for connecting the content of geometrical and mathematical subjects.

Mathematica is a program which is used as a numerical and symbolical calculator, computer language, a system for the visualization of functions and data, a platform for designing packages for specific applications and creating interactive documents with text, animations and sound, etc (Gorjanc, 2004).

Digitalized computation based generative modeling tools such as Rhino, Digital Project and Generative components are developed to manipulate complex building masses, facades, roofs, other exterior
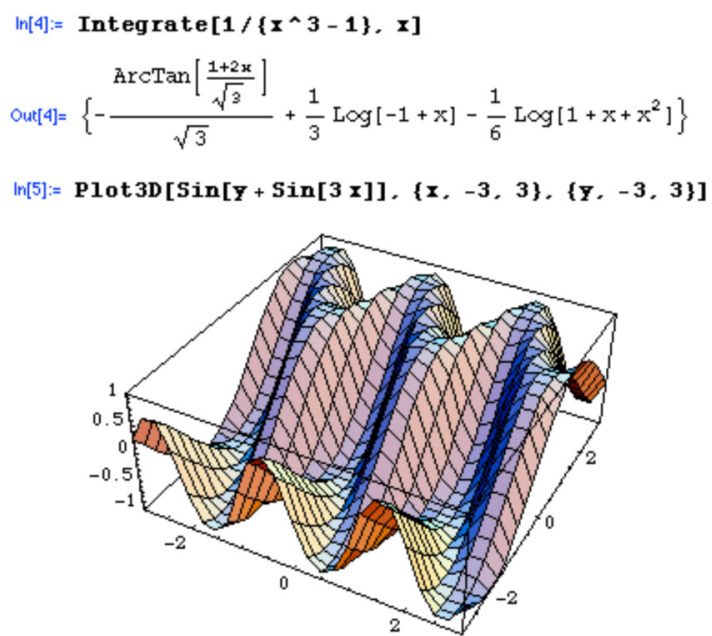

Out[5]= - SurfaceGraphics -

Fig.7. Geometry Study by Mathematica (Source: Mathematica V5, Wolfram Research)

building assemblies and even to construct detailed models (See Fig.8.). It helps designers to easily generate complicated forms in 3D models at all levels of familiarity with digital modeling. It also helps designers efficiently explore design variations with very few manual operations and provides mechanisms to store and accumulate design knowledge in digital formats (Bldgsim, 2008).
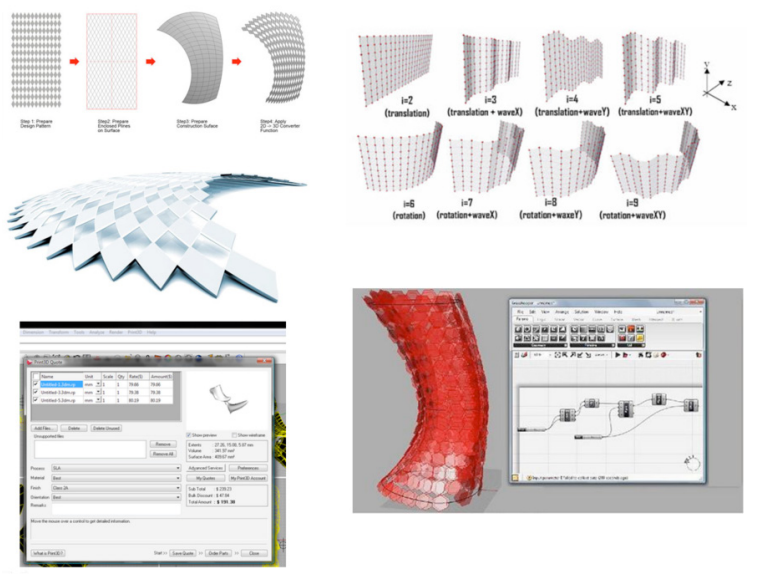

Fig.8. 3D Geometry Study using Rhino

(Source: Woo S., Grasshopper workshop, http://woojsung.com/)

Architects also have been applying software which was developed for the aerospace industry to design their buildings. While Frank Ghery was producing generative design, he realized that the traditional method of practice based on the documentation and delivery system was not suitable to capture his innovative designs. Gehry built a team of technologists and practitioners which initiated new ways of thinking about architecture and building, using advanced $3 \mathrm{D}$ aerospace technologies to design, document and go directly from design to construction without intermediate paper documentation. 
Frank Gehry uses the Catia software system developed by the French aerospace company, Dessault Systems to translate the complex geometries of his famous museum forms from three-dimensional working models into construction drawings. However, the Catia system was primarily designed as a manufacturing system, and is generally applied after a design or building shape has already been determined (Abel, 2004) (See Fig.9.).

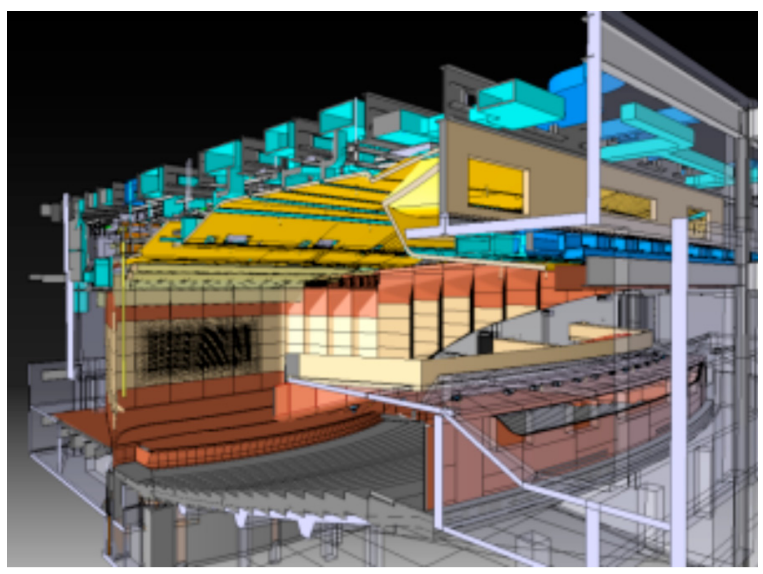

Fig.9. Digital Project (Source: Ghery Technologies)

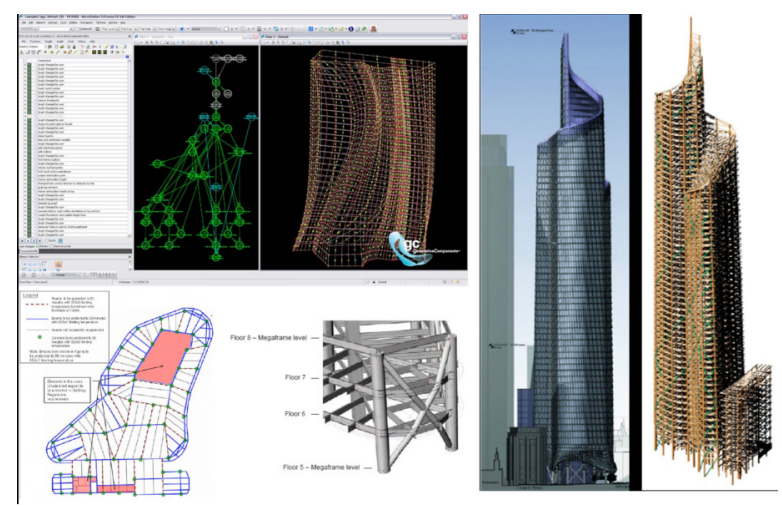

Fig.10. Use of Generative Components in Tall Building Practice (Source: Bentley \& Arup)

Generative components on the other hand, allow the designer to programmatically define a conceptual rule-set which the software can use to automatically generate a geometric response. This is a significantly different approach compared to conventional digital modeling where the designer must manually instantiate each geometric element. It eventually translates the designer's architectural concepts mathematically and programmatically (See Fig.10.).

Sang Min Park presented important research for his PhD Dissertation at the Illinois Institute of Technology which related to employing a digitally based design process for the comprehensive generation and variation of tall building forms (See Fig.11.).

Using Auto LISP programming language, a series of design variations were parametrically generated for tall building forms based on various geometric and

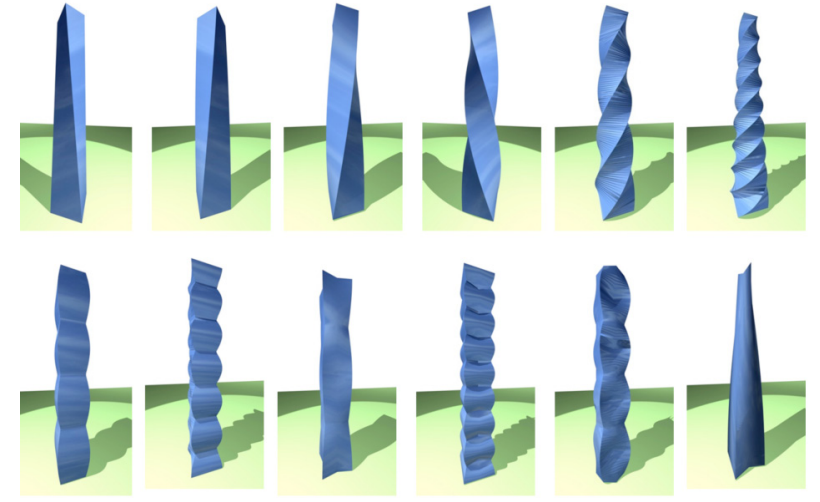

Fig.11. Tall Building Generation Process by Parametric Design (Source: Park S.)

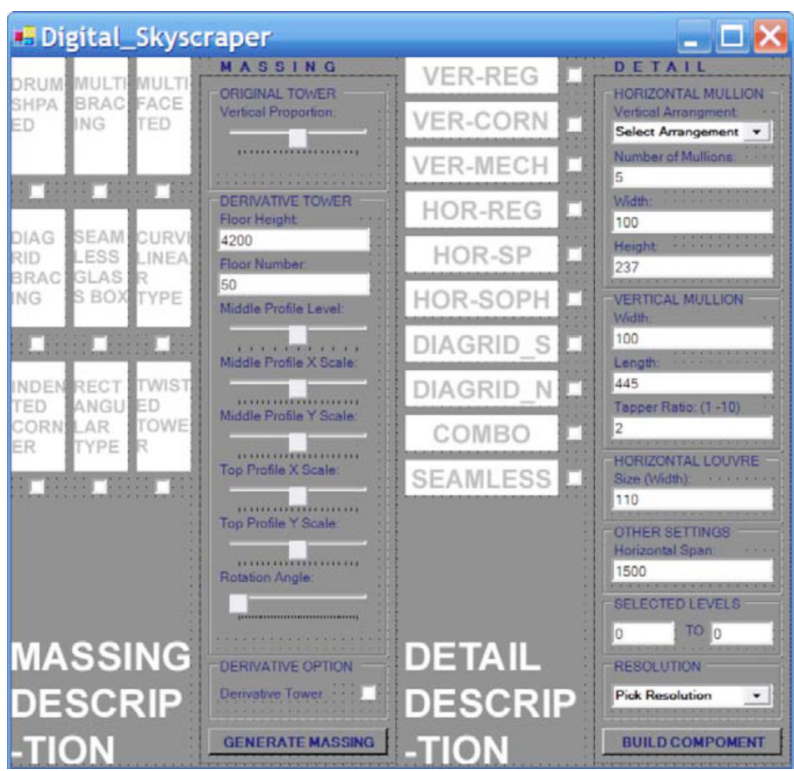

Fig.12. Tall Building Generation Process by Digital Skyscraper (Source: Chen S.)

architectural design considerations including building function, lease span, floor-to-floor height and core planning.

Mr. Shouheng Chen has proposed embedded methods as an alternative approach and to develop a digital system that can both handle complex forms and enable architects to work more efficiently in the early stages of the design process.

The intention behind the system is to relieve architects from the repetitive work that is required by conventional CAD systems as well as to allow them to carry their previous expertise and approved components into the design of new skyscrapers (See Fig.12.).

\section{Current Tall Building Design Practice}

Because of the advancement in structural engineering and curtain wall construction, architects today can essentially build as high as they like. The desire to build taller and taller skyscrapers is no longer a major concern for many skyscraper designers. Instead, it is 
the formal, technical, and ecological complexities of today's skyscrapers that challenge architects and leads innovation in the design of skyscrapers (Chen, 2007).

Recent trends also seek non-orthogonal treatments of building masses and forms to improve building performance; for example by minimizing outer facade/ floor surface ratio to decrease material usage/cost/ energy consumption, or by optimizing wind flow to reduce wind damage or activate wind generators. The geometrical complexity of high-rises is increasing rapidly, and by implication the complexity of materializing their facades and superstructures (Vollers, 2008).
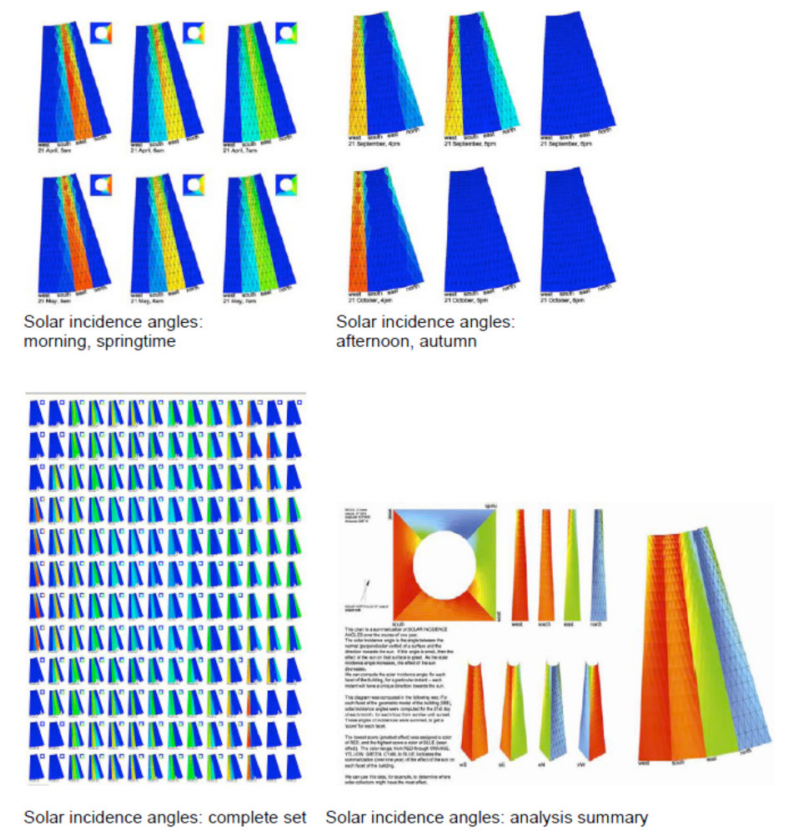

Fig.13. Lotte Tower Project

(Source: SOM)

The close integration of CAD/CAM and the advent of rapid prototyping machinery have become very important to support the sophisticated construction of complex forms generated by these capable design tools.

On the manufacturing side, it can be used to facilitate product design and the development process, thereby increasing product quality (Joo, 2006).

By using generative digital modeling tools integrated with BIM, SOM was able to analyze a variety of performative conditions such as ascertaining the size of specific curtain wall panels thereby shortening the lead time for fabrication, delivery, and installation. The benefit of this integrated digital design process has led to reduced costs for the Lotte Tower project in Korea (See Fig.13.).

The program generates one quarter of the structure, and uses symmetry to complete the models.

Parameters in the program control the diagrid; the parameters are refined after much iteration to optimize structural performance, program area contained within
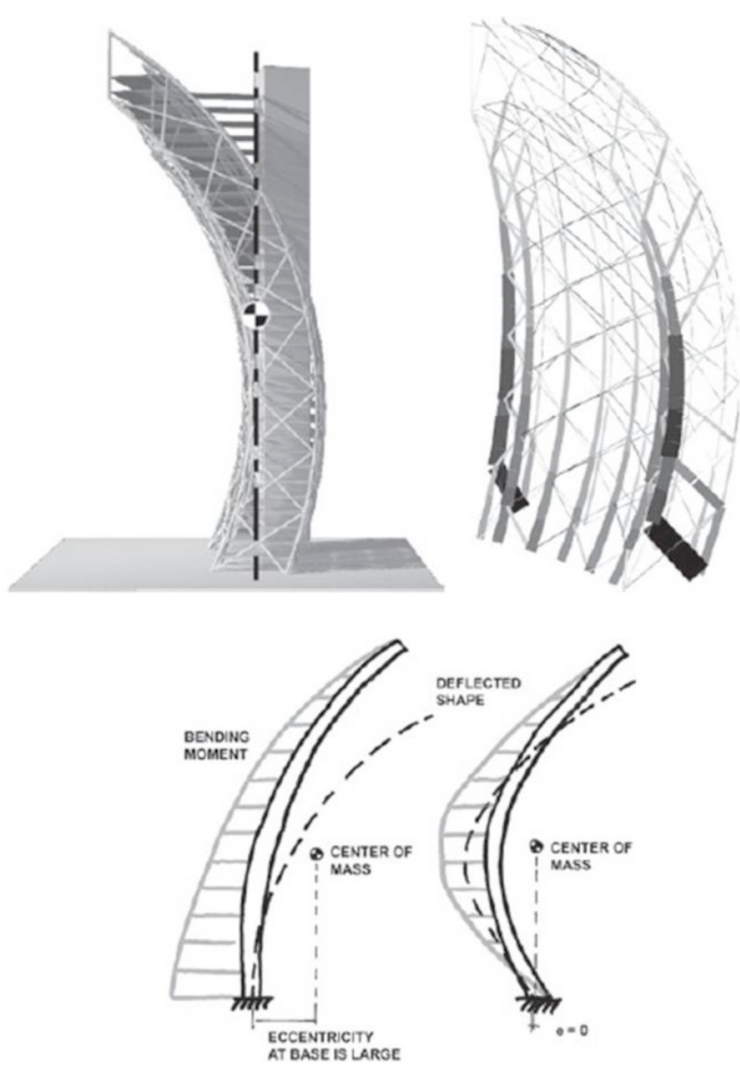

Fig. 14. Milan Fiera Tower

(Daniel Libeskind \& Arup)

the building, and aesthetic judgments (Katz, 2008).

In the 22-story Milan Fiera Tower by Daniel Libeskind, the tower is formed from a section of a spherical shell. The curvature, and centroid of the sphere from which it is cut, were varied parametrically to find a form, which located the center of the mass of the tower directly over the base (See Fig.14.). This allows a uniform arrangement of foundations. The Milan Fiera Tower uses a structural steel diagrid system to resist overturning and wind loads by mobilizing the full perimeter structure.

The diagrid can be preset to reduce the effects of self-weight movement. Upon completion the diagrid is finally connected to the vertical elevator core, which is not subject to any lean forces (Scott D, 2008).

Diagrid as a very thin, self-reliant structure effectively spreads its mass from its center and thus develops strength and resistance against forces from multiple sources and directions.

Even though the supporting structural systems behind the free forms vary depending on the projectspecific situations, diagrids are often employed as primary structures for free-form tall buildings as can be seen in Daniel Libeskind's Fiera Milano Tower and Morphosis' Phare Tower in La Defense (Moon, 2007).

The Swiss Re Building is one of the first, iconic, executed large-scale diagrid structures that have the ability to resist lateral forces due to the stiffness inherent in their simplicity and shape (See Fig.15.). 


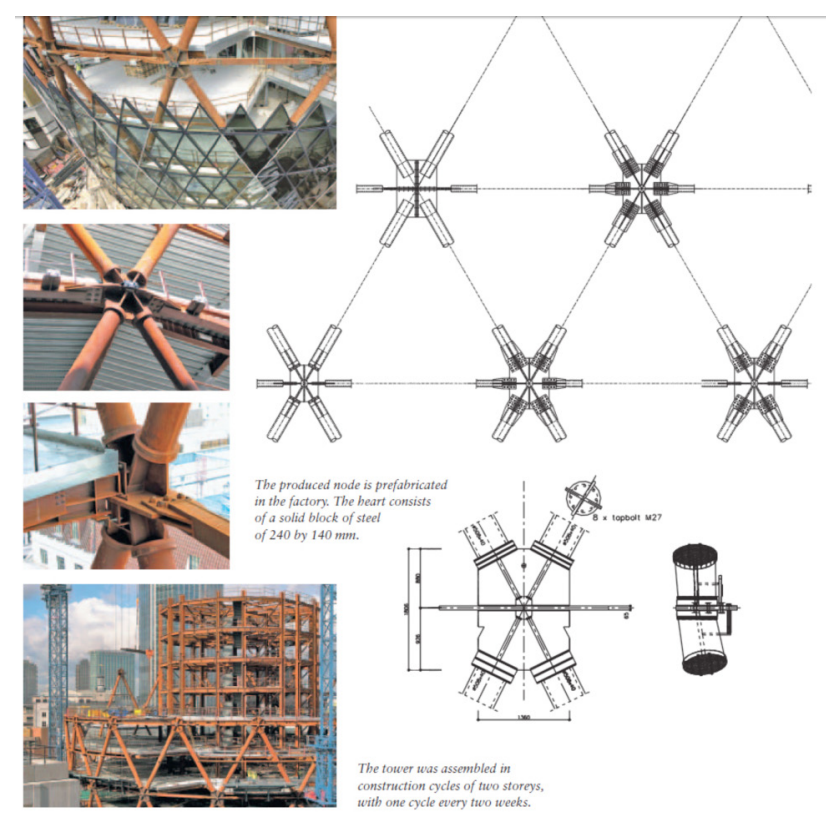

Fig.15. Diagrid System, Swiss Re Building (Source: Arup)

Design, procurement and fabrication processes were integrated through the use by the design team of three-dimensional modeling of the steel frame and a parametric approach to the design, enabling complexity to be managed with reduced risk and greater economy. The project shows the ability of structural steel to enable radical architectural ideas to be realized (Munro, 2004).

Most diagrid systems employed today are constructed of steel, as is the Swiss Re Building, or Hearst Tower. The exploitation of steel's compressive and tensile abilities allow contractors to use less steel in construction, for instance in the Hearst Tower in NYC, it has been estimated that $20 \%$ less steel was required compared with the typical moment frame (See Fig.16.).
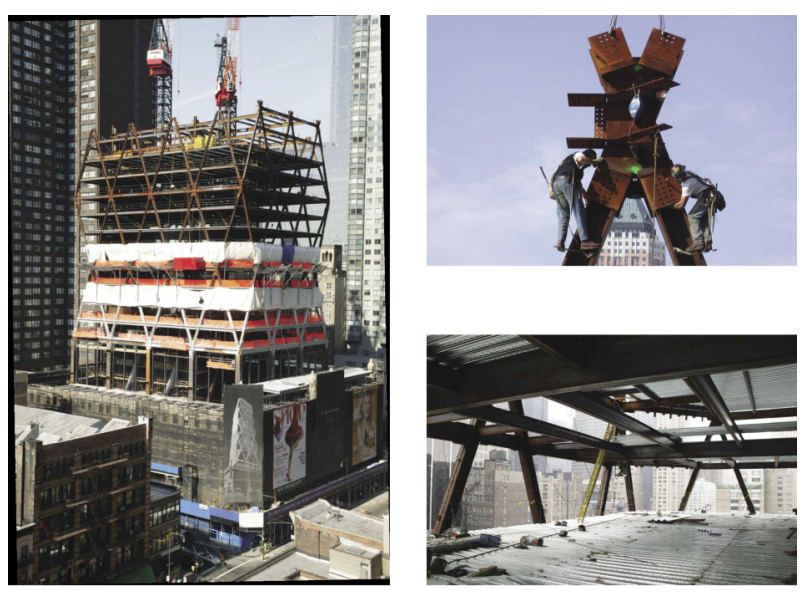

Fig.16. Diagrid System, Hearst Tower (Source: Metals in Construction)

Mr. Gün O demonstrates different strategies developed for subdividing complex-geometric surfaces. Concerning the problems of geometric post-rationalization, he highlights the importance of incorporating the information related to construction limitations into the design process (See Fig.17.).

Parametric modeling is not a solution tool for design but a new area of inquiry for it, since every design problem now demands custom approaches, analyses and applications in the parametric modeling environments.

Today, an architect capable of customizing his/ her tools by digital means will be able to express and realize their design intentions more solidly in the digital environment (Gün, 2007).
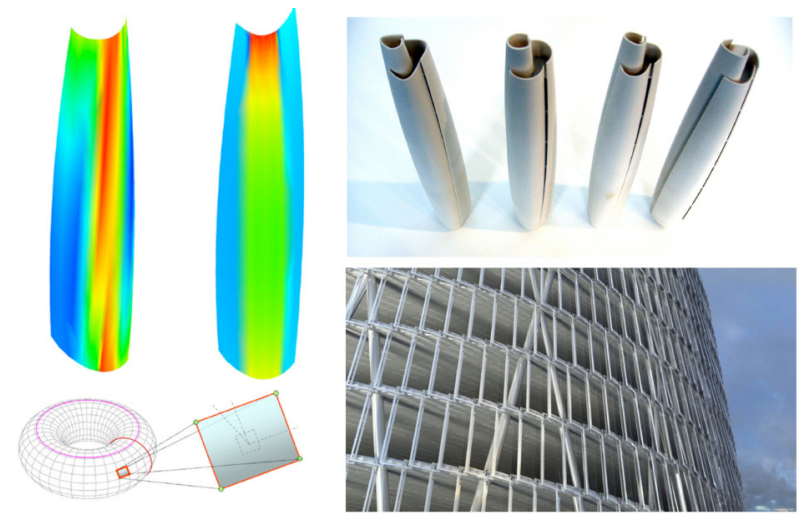

Fig.17. Geometric Reconstruction and Rationalization (Source: Gün O, KPF)

\section{Structure-Architecture Interaction}

Tower 29 not only possesses an iconic form, but also responds favorably both structurally and environmentally. The collaborative effort between the architect and the engineer yielded a structure that blends very well with the form and enables it to express itself in a magnificent way (See Fig.18.).

The challenge for the architect in designing Dubai Tower 29 was not only that it had to be original, but also that he had to dig deep into his creative mind to pursue a unique and exciting (iconic) building. On the other hand, the challenge for the engineer was two fold: (1) to preserve the architectural vision and (2) to maintain the structural integrity (Elnimeiri, 2008).

The structural concept began to develop and fit naturally for most of the parts, and the elements of the structure began to emerge and claim their place within the architecture.

Perhaps the innovation in the structural system stems from the fact that the structure capitalized on the potential of the form to yield an efficient structure. The process was not an easy one, but went through many complex steps that included visualization, model building, both physical and digital, and many simulations. But, in the end it was the creative endeavor between the architect and the engineer that led to the successful outcome. 

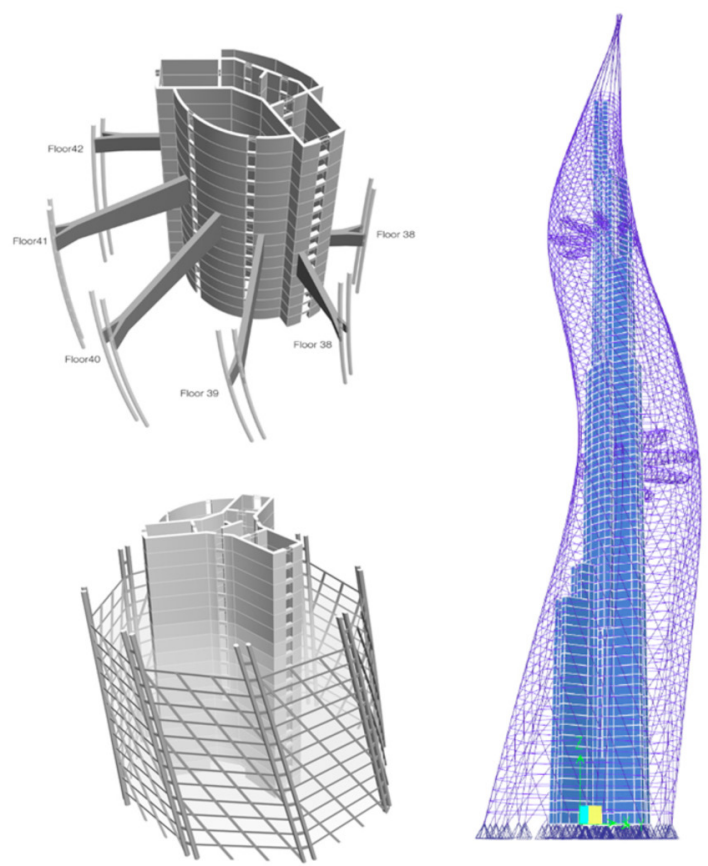

Fig.18. Dubai Tower 29

(Source: Elnimeiri, M., CDCi)

\section{Implementations and Conclusion}

Advancement in digital tools brings significant benefit and change in tall building design. During the 2008 fall and 2009 spring semester of the Tall Building Design Studio at IIT, the author was able to implement diverse ideas into a generative form by using a number of different tools.

Figs.19.-21. show tall building designs by graduate students at the Illinois Institute of Technology under the author's supervision.

A series of parametric approaches were tested and implemented to find the direct and indirect relation to the resulting form and significant efforts were made to incorporate a structural system within an architectural form generation process using the Autodesk Revit (See Fig.19.).
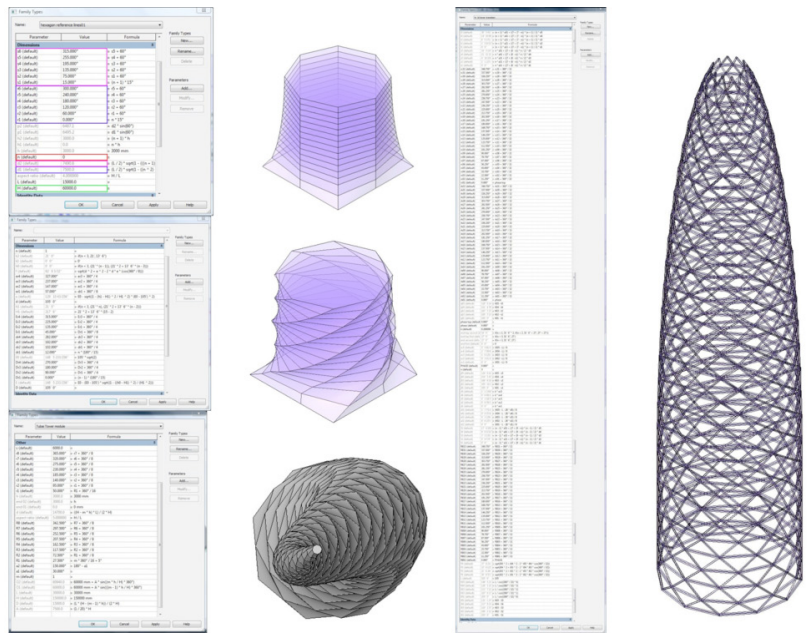

Fig.19. Tall Building Design Project at IIT (Source: Liu, X. and Kim, H)

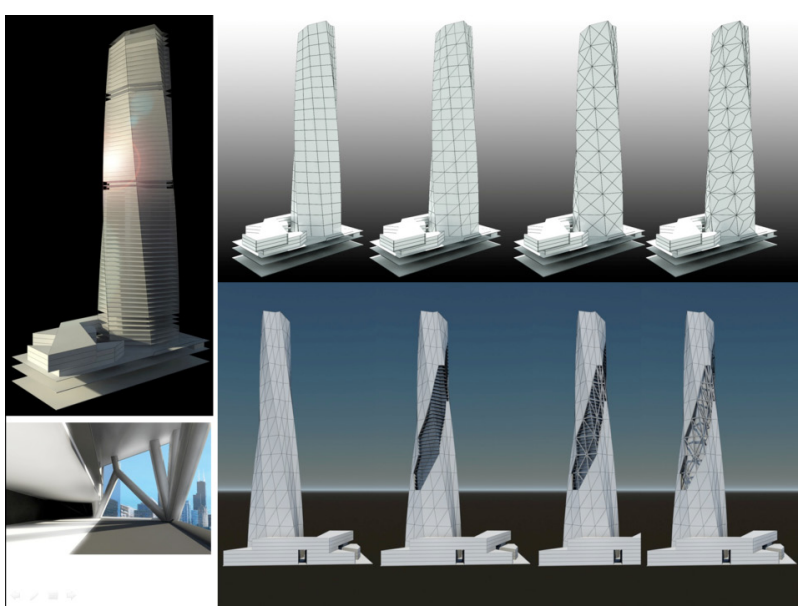

Fig.20. Tall Building Design Project at IIT (Source: Labuda, T. and Kim, H.)

Fig.20. shows a study of structural patterns and the threshold of the incorporation process while pursuing form generation. Generative ideas have been implemented and incorporated with efficient structural solutions.

Fig.21. shows the final rendering of a mixed-use tall building project at the Illinois Center in Chicago with a complex geometry, which was generated using generative components at the initial form finding stage.

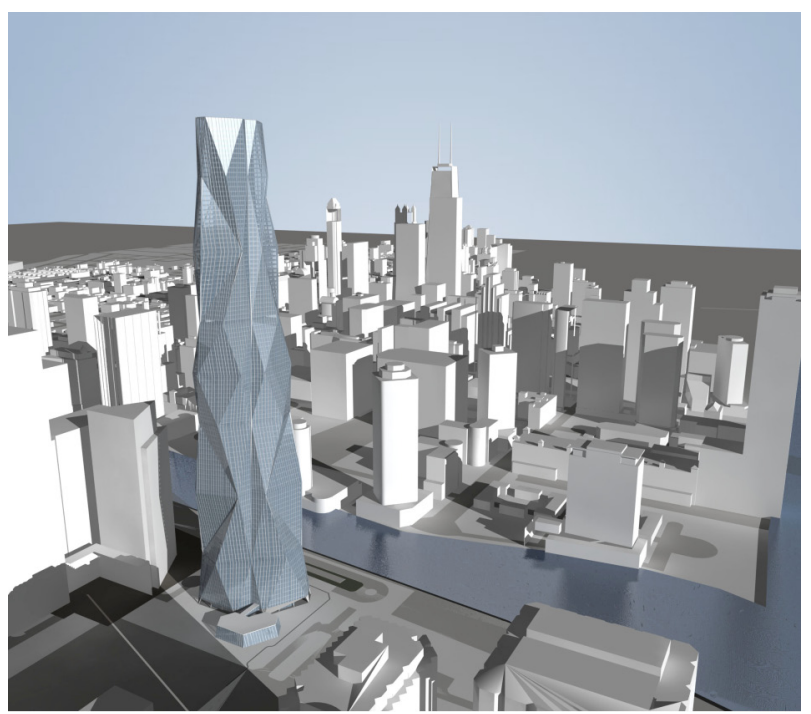

Fig.21. Tall Building Design Project at IIT (Source: Abdolhussein, F. and Kim, H.)

The paradigm is shifting to processes of form generation based on performance design strategies. The convergence of generative and analytical tools used in the early stages of design provides great opportunities for the exploration of architectural form and helps designers and architects move away from traditional approaches.

However, the author and students discovered a difficulty concerning the potential of incorporating the qualitative and quantitative aspects of building performance including structural and environmental 
systems while implementing these tools to find building forms.

The current trend in architectural design is considered to overemphasize aesthetics and style while paying less attention to required optimization through the realization process.

The design approaches presented in this study may enable solutions that perform well with reference to the necessary discipline while pursuing significant benefits of design variation by using current digital design tools.

\section{Acknowledgement}

This work was supported by the Sustainable Building Research Centre of Hanyang University, which was supported by the ERC program of the Ministry of Education, Science and Technology (\#R112005-056-04003-0). The authors also recognize the College of Architecture at IIT and graduate students of the Tall Building Design Studio.

\section{References}

1) Andres M (2009) Genetic Exploration of Biological Micro Structures for Architectural Applications, Stand Up Architecture: Structural DNA, http://sa-mariavera.blogspot.com/.

2) Abel, C. (2004) Architecture, Technology and Process, Oxford, UK: Elsevier.

3) Bldgsim (2008) Parametric Design Tool based on Rhino, Tools for Better and more Sustainable Building Design, http://bldgsim. wordpress.com/2008/10/09/parametric-design-tool-based-onrhino/.

4) Chen, S. (2007) Embedding Methods for Massing and Detail Design in Computer Generated Design of Skyscrapers, M.S Thesis, MIT.

5) Elnimeiri, M. (2008) Dubai Tower 29, Structure and Form, Proceedings, CTBUH 8th World Congress.

6) Gorjanc, S (2004) Some Examples of Using Mathematica and webMathematica in Teaching Geometry, Journal for Geometry and Graphics, 8(2), pp.243-253.

7) Gün O (2007) Composing the Bits of Surfaces in Architectural Practice: Methodologies and Codes for Generation, Rationalization, and Analysis of Non-Standard Geometries, eCAADe 25 .

8) Joo, J. and Kovidvish, K. (2006) Soft Skin Skyscraper: Digital Design and Fabrication for Tall Building Façade, Digital Mock-up Workshop.

9) Juarez, A. (2000) Topology and Organicism in the Work of Louis I. Kahn. Notes on the City Tower, Yale School of Architecture.

10) Katz, N. (2007) Parametric Modeling in AutoCAD, AECbytes Viewpoint \#32, http://www.aecbytes.com.

11) Kulic, V. (2001), The complexity of architectural form: some basic questions, Complexity International Vol.8, http://www.complexity. org.au/.

12) Moon K (2007) Structural Developments in Tall Buildings: Current Trends and Future Prospects, Architectural Science Review 50(3), pp.205-223.

13) Munro, D. (2004) Swiss Re's Building, London, NR 3, NYHETER OM STÅLBYGGNAD, pp.36-43.

14) Pawley, M. (1987) Technology Transfer, Architectural Review, No.1087, pp.30-39.

15) Schodek, D. (1998) Structures, 3rd Edition. Upper Saddle River, NJ: Prentice Hall.
16) Scott, D., Farnsworth, D., Jackson, M., and Clark, M. (2007) The Effects of Complex Geometry. The Structural Design of Tall and Special Buildings Build. 16, pp.441-455.

17) Thurnauer, M. (2006), From Design to Fabrication: Precast Concrete with FormZ, FormZ Joint Study Report, pp.74-76.

18) Voller, K. (2002) Morphological Scheme of Second-Generation Non-Orthogonal High-Rises, Delft University of Technology, Netherlands.

19) Wong, H. (2008), Canopy, Digital Design and Application. 